\title{
Implementation of Dynamic Voltage Restorer to Improve the Voltage Stability of a multi Bus System
}

\author{
B Venkateshnaik ${ }^{1}$, A Nagaraju ${ }^{2}$, Sindhu $\mathrm{M}^{3}$ \\ ${ }^{1}$ GITAM, India, vbanakar@gitam.edu \\ ${ }^{2}$ GITAM, India, nangajal@gitam.edu \\ ${ }^{3}$ UVCE, India, sindhusudharshanks@gmail.com
}

\begin{abstract}
In this rapidly growing universe, the growth of electrical network is also very fast. Maintaining a good voltage profile is also very challenging and difficult task in complex networks. Voltage has to be stable in each and every conditions while compensating both before occurrence of fault and after occurrence of fault. If we don't maintain the proper reactive power in an electrical system than the voltage stability will collapse. Whenever fault occurs in any point of an electrical network there may be possibilities of collapsing voltage stability and mismatch in requiring reactive power. We need to give or supply the reactive power to improve the voltage stability of the system. The reactive power compensation can be done either in parallel way or by having series compensation. Usage of FACTS devices in compensation of reactive power is very common practice. For shunt compensation usage of STATCOM is very common, but it helps in improving power factor of the network if we want to improve the voltage profile then we must go for series compensation for better result. In this paper we have used dynamic voltage restorer. A load flow analysis has done on a standard electrical multiple bus system by using Newton rapson technique and the results have analyzed before and after series compensation. Matlab simulation is used for this study.
\end{abstract}

Key words: Dynamic voltage restorer, Static synchronous compensator, flexible AC transmission system.

\section{INTRODUCTION}

Extension of power system network and increase in the demand in a frequent way, the controllability action also need to build in a proper way. A strategy on controlling the system voltage stability done on a standard multiple electrical bus system. The control of reactive power either for compensation or to get back has done. Matlab is a power full tool for the purpose of conducting the load flow analysis by using various mathematics tools. A proper location and size the FACT device has been identified to enhance the voltage stability and to overcome the shortage in supply of reactive power. A test has been carried out in matlab with the help of tangent vector method and also considered both the cases of with and without FACT device that is STATCOM [1]. More than two indices of voltage stability been taken and reactive power maintenance in the system had performed on a standard on multiple electrical bus system. Here all the types of compensation had tested that is series, parallel and combination of these two [2]. Transient voltage stability has been carried out in power grind. Identification of location of fault and compensation of reactive power done by using FACTS devices through mat lab simulation [3]. [ A new technique called modified voltage stability indices to perform the voltage stability analysis on multiple bus system. A $230 \mathrm{kv}$ network has been modeled and the analysis has done in matlab simulink [4]. A new algorithm has been proposed which works on the novel pattern recognition technique. Here simulation data and its output had obtained by in matlab simulink and by observing the results the faulted bus has been identified. After identification of faulted zone a proper compensation technique is implemented to supply the reactive power and the stability of network is maintained in a healthy way [5]. With help of voltage quadratic equations used in power flow analysis various parameters in the analysis like voltage, current, power all measured and simaltenous analysis is carried it in a matlab simulation by using a standard IEEE bus system. A device used for compensation of reactive power a placed in a specific location and stability is measured [6]. A realization of closed loop control system for optimization reactive power in automatic voltage control in a load dispatch center is performed. Where a proper FACT device is used for the implementation of compensation of reactive power in a faulty section and result is observed in matlab simulink [7]. As we all know those synchronous motors and the static var compensators plays an important role in stability of the electrical network, a proper compensation device is used to supply of reactive power. This will be helpful under voltage loss condition and also avoids collapsing in the stability of the system [8]. A new algorithm known as decision tree algorithm is used in the analysis of the voltage stability in a power grid. Based on the results obtained by using this algorithm a faulty locality is identified and a proper compensation technique is used save and balance a 
complex electrical system. This performance is done on a standard IEEE 39 bus system [9]. A new optimization technique is proposed to establish the relationship between controlled variables and controlling voltage. The analysis is carried out on s small 5 bus system and stability of the system is measured in matlab simulation [10].

\section{SOLUTION APPROACH}

\subsection{Identification of weak bus}

We have used newton raphson technique to conduct a load flow analysis on a standard electrical multibus system. Following equation is used in newton raphsnon technique. We have formed a jacobian matrix shown in equation 1 and it has sub matrices as J1, J2, J3 and j4. The load flow analysis's is done in matlab and the results has pasted in the result section. We have taken $7^{\text {th }}$ bus is weakest bus by using load flow analysis, where we have assumed that fault has occurred at $7^{\text {th }}$ bus.

$$
\begin{aligned}
& \Delta P \\
& \Delta Q
\end{aligned}=\left[\begin{array}{ll}
J_{1} & J_{2} \\
J_{3} & J_{4}
\end{array}\right] \Delta V
$$

\subsection{Voltage collapse mechanism}

In any electrical network either in transmission or distribution once the system gets damaged by any kind of fault the voltage at that point will get decreased sue to increase in the reactive power demand. Especially the transmission lines, transformers are much more affected to these phenomena hence we need save and balance a complex network of an electrical system by supplying the proper reactive power by using various FACTS devices.

\subsection{Reactive power}

The power which will flow forth and back in an electrical network. We need to have the sufficient reactive power in an electric network to supply or deliver the voltage to the load through transmission lines. The power triangle is shown in figure 1.

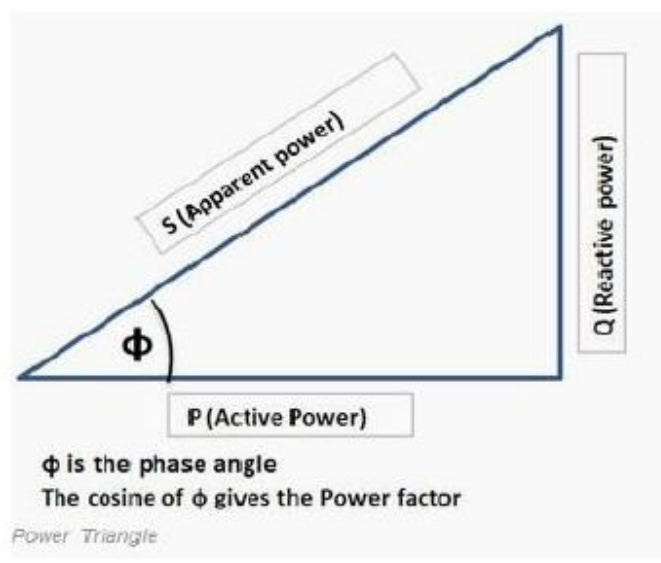

Figure1: Power triangle

\subsection{Facts Controllers}

These are the power electronics devices used for the proper operation of power system to meet the require demand in a profitable way. These are the most favorable devices for the power transfer capability of the network with minimal amount of losses. In our paper we have used dynamic voltage restorer for series compensation of the power known as reactive power.

\subsection{Power system controllability}

Figure 2 shows the power system network variable can be easily controlled smoothly with minimal cost by using FACTS devices.
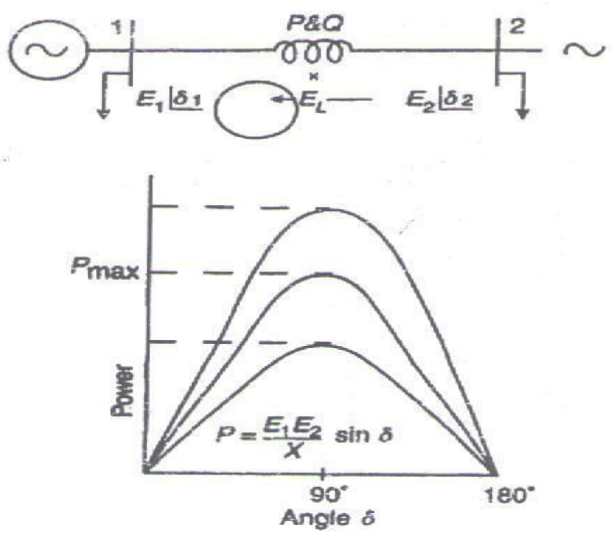

Figure 2: Power system controllability

\section{DYNAMIC VOLTAGE RESTORER}

It is FACTS device where more effectively adopted for series balance and maintenance of reactive power. Among all the power quality issues voltage sag is more severe than any other issues, hence it is very important to overcome this issue to maintain the voltage stability by using dynamic voltage restorer.

\subsection{Location of a dynamic voltage restorer}

DVR is a series connectable device where it can adopted along with the line which is to be protected. The DVR is located at the load side where voltage needs to be boosted. Whenever voltage sag type power quality issues will occurs in load side of power system, DVR will step will supply the dropped voltage to the load through step down transformer. Hence a DVR always connected in series with the line of load. Supply voltage side transformer and the DVR will meet up at a common point known as the point is same and coupled with other lines. 
B Venkateshnaik et al., International Journal of Emerging Trends in Engineering Research, 8(8), August 2020, 4173 - 4177

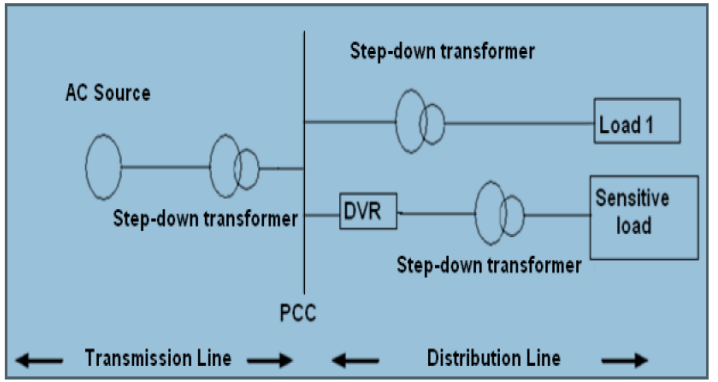

Figure 3: Location of a dynamic voltage restorer (DVR)

\subsection{Dynamic Voltage Restorer (DVR) general configuration}

A DVR is always adopted and fixed along with the line across the transformer. Whenever there is fault occurs and additional voltage is required the voltage will be generated with the help of voltage source inverter. Harmonic filters are used to remove the harmonic present in the voltage which is coming from voltage source inverter. Energy storage device is nothing but either batteries or flywheel used as input for the voltage source inverter. A control circuit is used to supply contact magnitude of voltage irrespective of load fluctuations. General configuration of DVR is shown in figure 4

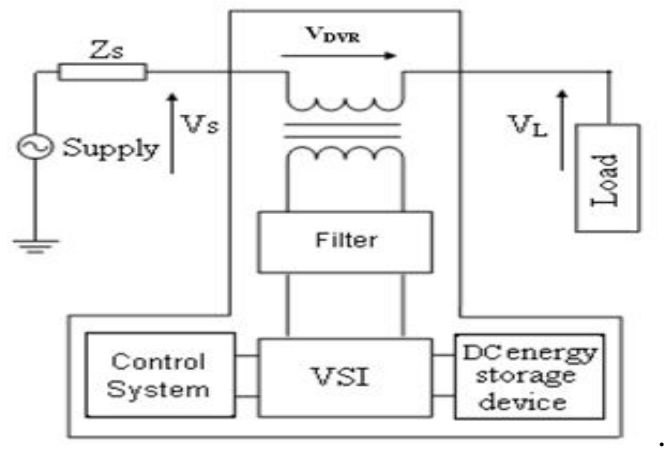

Figure 4: Dynamic Voltage Restorer (DVR) general configuration

\section{MATLAB SIMULINK MODELLING}

In matlab simulink a standard a standard electrical multibus system is simulated and treated as test system. Fir that test system fault is injected, for injecting fault a DVR is connected to overcome the fault. Fault is injected at bus number 7. A Test system without fault is shown in figure 5 .

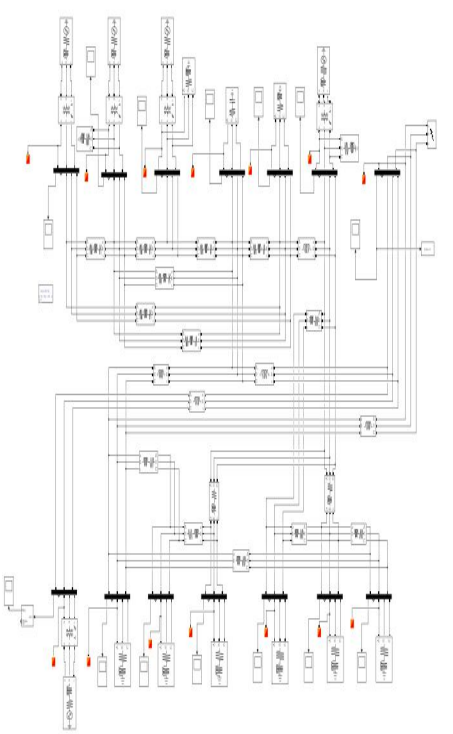

Figure 5: Test system without fault

A Test system without fault is shown in figure 6 .

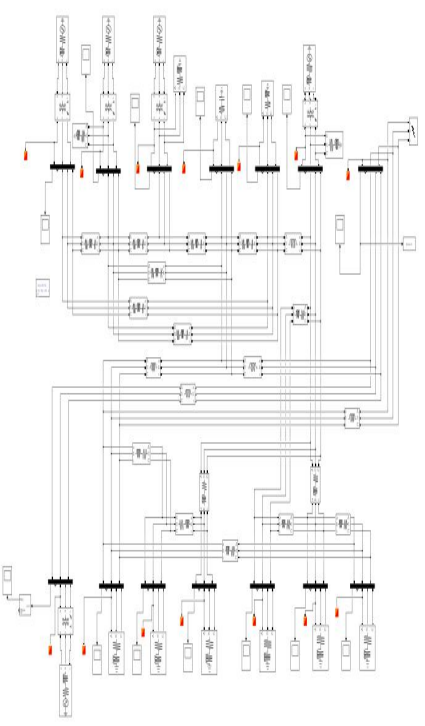

Figure 6: Test system with fault

A DVR simulink model is shown in figure 7.

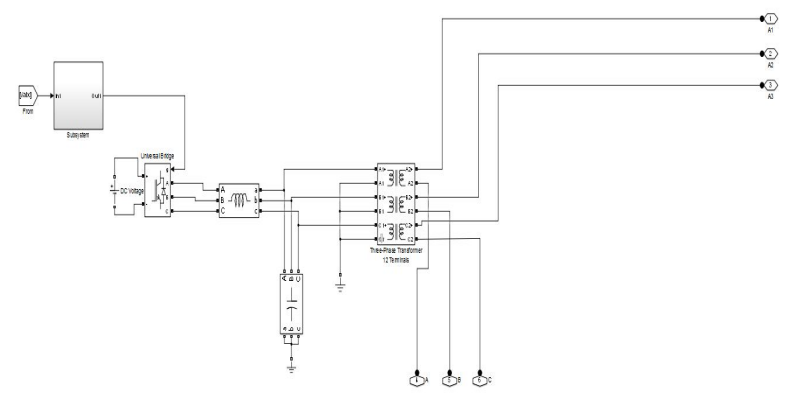

Figure 7: DVR simulink model 
A Test system with DVR is as shown in figure 8

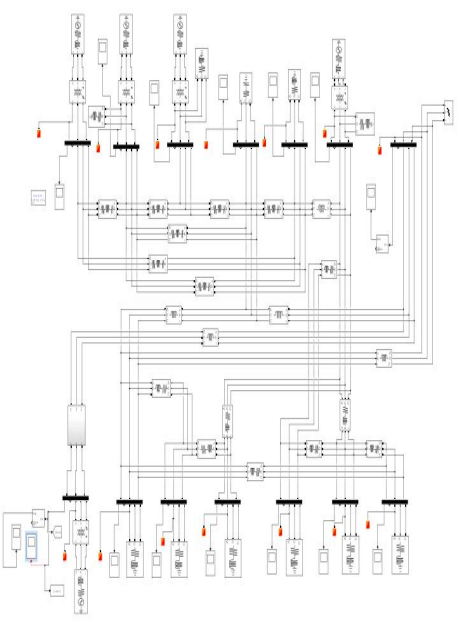

Figure 8: Test system with DVR

\section{RESULTS}

The readings obtained from load flow analysis and the waveform of various parameters performed in matlab simulink at different conditions is shown below. By using newton raphon method, in table one all the parameters at bus number 7 is fine and also the waveform of voltage is pure sinusoidal., but when fault occurs at bus 7 the table 2 shows the values of all the parameters and also the voltage waveform varies from sine wave. This can be improved by connecting a DVR in series with the bus and again the load flow analysis done as shown in table 3.

Table 1: Load flow study results before fault

\begin{tabular}{|c|c|c|c|c|c|c|c|c|c|c|c|}
\hline \multicolumn{3}{|c|}{ Blocktype Bustype Bus ID } & \multicolumn{7}{|c|}{ Vbase (KI) Vref (pu) Vangle (deg)) P(MM) Q(Mv.... Qmin (Mvar) Qmax (Mvar) } & \multicolumn{2}{|c|}{ V_LF (pu) Vangle LF (deg) } \\
\hline 1 Bus & - & BOS_ 1 & 0.00 & 1 & 0.00 & 0.00 & 0.00 & 0.00 & 0.00 & 1.1863 & -8.40 \\
\hline 2 RIC load & & BUS_2 & 0.00 & 1 & 0.00 & 0.00 & 0.00 & $-\operatorname{Inf}$ & Inf & 1.2040 & 15.94 \\
\hline 3 RiC load & & BOS 11 & 0.00 & 1 & 0.00 & 0.00 & 0.00 & $-\operatorname{Inf}$ & $\operatorname{Inf}$ & 1.8865 & -136.41 \\
\hline 4 RIC load & & BUS__12 & 0.00 & 1 & 0.00 & 0.00 & 0.00 & $-\operatorname{Inf}$ & Inf & 1.9117 & -143.00 \\
\hline 5 RIC lood & & BUS_13 & 0.00 & 1 & 0.00 & 0.00 & 0.00 & -Inf & $\operatorname{Inf}$ & 1.9039 & -142.41 \\
\hline 6 RIC load & & BUS_14 & 0.00 & 1 & 0.00 & 0.00 & 0.00 & $-\operatorname{Inf}$ & Inf & 1.8367 & -139.24 \\
\hline 7 RLC load & & BUS_3 & 0.00 & 1 & 0.00 & 0.00 & 0.00 & $-\operatorname{Inf}$ & Inf & 1.4373 & -72.13 \\
\hline 8 RIC lood & & BDS 4 & 0.00 & 1 & 0.00 & 0.00 & -0.00 & -Inf & Inf & 1.4502 & -38.10 \\
\hline 9 RLC load & & BUS 5 & 0.00 & 1 & 0.00 & 0.00 & 0.00 & $-\operatorname{Inf}$ & $\operatorname{Inf}$ & 1.4278 & -28.12 \\
\hline 10 RLC load & & BUS 6 & 0.00 & 1 & 0.00 & 0.00 & 0.00 & $-\operatorname{Inf}$ & Inf & 1.7675 & -124.48 \\
\hline 11 Bus & - & BUS_? & 0.00 & 1 & 0.00 & 0.00 & 0.00 & 0.00 & 0.00 & 1.8420 & -99.02 \\
\hline 12 Bus & - & BUS 8 & 0.00 & 1 & 0.00 & 0.00 & 0.00 & 0.00 & 0.00 & 1.9996 & -101.62 \\
\hline 13 RIC load & & BUS_9 & 0.00 & 1 & 0.00 & 0.00 & 0.00 & -Inf & $\operatorname{Inf}$ & 1.8451 & -134.86 \\
\hline 14 RIC load & & BUS_10 & 0.00 & 1 & 0.00 & 0.00 & 0.00 & $-\operatorname{Inf}$ & $\operatorname{Inf}$ & 1.8687 & -140.90 \\
\hline 15 Varc & $\mathbb{N}$ & $1 *$ & 0.00 & 1 & 0.00 & 0.00 & 0.00 & -0.00 & 0.00 & 1.6534 & -132.14 \\
\hline 16 Varc & $\mathrm{NV}$ & $2{ }^{*}$ & 0.00 & 1 & 0.00 & 0.00 & 23.40 & -0.00 & 0.00 & 1.4336 & -155.01 \\
\hline 17 Varc & N & 4 & 0.00 & 1 & 0.00 & 0.00 & 0.00 & -0.00 & 0.00 & 0.7056 & 48.27 \\
\hline 18 Varc & $\mathbb{N}$ & $4^{4}$ & 0.00 & 1 & 0.00 & 0.00 & 23.40 & 0.00 & 0.00 & 1.0760 & -102.66 \\
\hline 19 Varc & gwing & $5^{4}$ & 0.00 & 1 & 0.00 & 0.00 & -0.00 & 0.00 & 0.00 & 1 & 0.00 \\
\hline
\end{tabular}

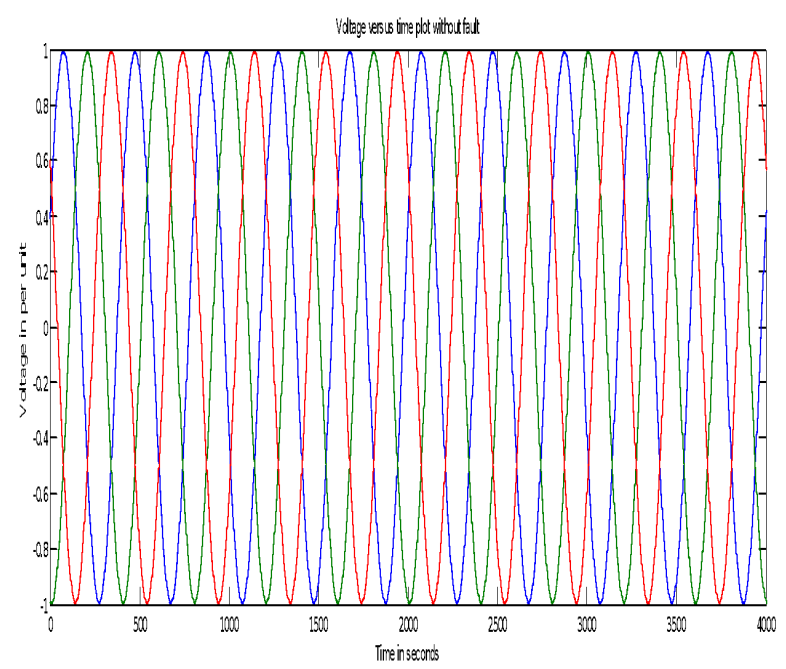

Figure 9: Voltage at bus number 8 before fault

Table 2: Load flow studies after the fault.

\begin{tabular}{|c|c|c|c|c|c|c|c|c|c|c|c|}
\hline \multicolumn{3}{|c|}{ Blocktype Bustype Bus ID } & \multicolumn{4}{|c|}{ Vhase (kN) Vref (pu) Vangle (deg) P PMW] } & \multicolumn{3}{|c|}{ Q(Mv... Qmin (Mvar) Qmaxi: (Mvar) } & \multicolumn{2}{|c|}{ V_LF(pu) Vangle_EF(deg] } \\
\hline 18 & Bug - & BUS:- & 0.00 & 1 & 0.00 & 0.00 & 0.00 & 0.00 & 0.00 & 0.3520 & -40.2 \\
\hline & RIC load PQ & EOS 2 & 0.00 & 1 & 0.00 & 0.00 & 0.00 & $-\operatorname{lnf}$ & $\operatorname{Inf}$ & 0.2455 & -38.0 \\
\hline & IIC load PO & BOS_11 & 0.00 & 1 & 0.00 & 0.00 & 0.00 & $-\operatorname{Inf}$ & $\operatorname{Inf}$ & 1.3206 & 124.3 \\
\hline & RIC load DO & BUS 12 & 0.00 & 1 & 0.00 & 0.00 & 0.00 & $-\operatorname{Inf}$ & $\operatorname{Inf}$ & 1.7825 & 103.6 \\
\hline 52 & RIC lood PO & BUS_13 & 0.00 & 1 & 0.00 & 0.00 & 0.00 & $-\operatorname{Inf}$ & $\operatorname{Inf}$ & 1.6958 & 106.8 \\
\hline 62 & RIC load 2 & BUS 14 & 0.00 & 1 & 0.00 & 0.00 & 0.00 & $-\operatorname{Inf}$ & $\operatorname{Inf}$ & 1.0515 & 128.4 \\
\hline $7:$ & RIC load PO & BOS 3 & 0.00 & 1 & 0.00 & 0.00 & 0.00 & $-\operatorname{Inf}$ & $\operatorname{Inf}$ & 0.0968 & -70.78 \\
\hline $8: 2$ & RIC Losd PO & BOS_: & 0.00 & 1 & 0.00 & 0.00 & -0.00 & $-\operatorname{Inf}$ & $\operatorname{Inf}$ & 0.0598 & $129.3^{\circ}$ \\
\hline $9:$ & IIC load DO & BUS 5 & 00 & 1 & 0.00 & 0.00 & 0.00 & $-\operatorname{Inf}$ & $\operatorname{Inf}$ & 1053 & 134.2 \\
\hline 102 & RIC load DO & BDS 6 & 0.00 & 1 & 0.00 & 0.00 & 0.00 & $-\operatorname{Inf}$ & $\operatorname{Inf}$ & 1.6997 & 110.6 \\
\hline 118 & Bus - & EOS_? & 0.00 & 1 & 0.00 & 0.00 & 0.00 & 0.00 & 0.00 & 0.2067 & 155.6 \\
\hline $12 \mathrm{~B}$ & Bus - & BOS 8 & 0.00 & 1 & 0.00 & 0.00 & 0.00 & 0.00 & 0.00 & 0.2101 & -29.58 \\
\hline $13:$ & IIC Lodd DO & BOS 9 & 0.00 & 1 & 0.00 & 0.00 & 0.00 & $-\operatorname{Inf}$ & $\operatorname{Inf}$ & 0.6235 & 124.1 \\
\hline $14:$ & RIC load PO & BUS_10 & 0.00 & 1 & 0.00 & 0.00 & 0.00 & $-\operatorname{Inf}$ & $\operatorname{Inf}$ & 0.8473 & 125.4 \\
\hline $15 \%$ & Vere $\quad \mathbb{P V}$ & $41 *$ & 0.00 & 1 & 0.00 & 0.00 & 23.40 & 0.00 & 0.00 & 0.7209 & -102.1 \\
\hline $16 \%$ & gxing & $2^{* *}$ & 0.00 & 1 & 0.00 & 0.00 & -0.00 & 0.00 & 0.00 & 1 & 0.00 \\
\hline 17 & Trerc & ${ }^{*} 3^{*}$ & 0.00 & 1 & 0.00 & 0.00 & 0.00 & -0.00 & 0.00 & 0.9250 & -62.2 \\
\hline 187 & Varc & $* 4 *$ & 0.00 & 1 & 0.00 & 0.00 & 0.00 & -0.00 & 0.00 & 0.7717 & -58.98 \\
\hline 197 & Vare & $* 5^{*}$ & 0.00 & 1 & 0.00 & 0.00 & 23.40 & -0.00 & 0.00 & 0.3884 & 78.5 \\
\hline
\end{tabular}

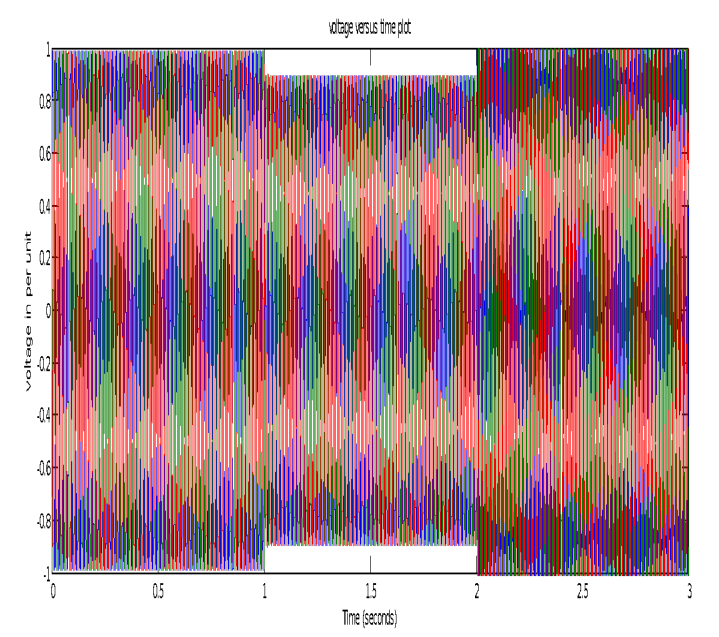

Figure 10: Voltage at bus 8 after the fault 
B Venkateshnaik et al., International Journal of Emerging Trends in Engineering Research, 8(8), August 2020, 4173 - 4177

Table 3: Load flow studies after connecting DVR.

\begin{tabular}{|c|c|c|c|c|c|c|c|c|c|c|c|}
\hline \multicolumn{3}{|c|}{ Blocktype Bustype Bus ID } & \multicolumn{3}{|c|}{ Vbase (Kh) Vref (pu) Vangle (degg) } & \multicolumn{4}{|c|}{ P (MM) Q Q(Mv... Qmin (Mvar) Qmax (Mvar) } & \multicolumn{2}{|c|}{ VLLF(pu) Vangle_LF (deg) } \\
\hline 1 Bus & - & BOS_ 1 & 0.00 & 1 & 0.00 & 0.00 & 0.00 & 0.00 & 0.00 & 0.4043 & -56.7 \\
\hline 2 RIC $10 \mathrm{~s}$ & & BOS $2_{-}$ & 0.00 & & 0.00 & 0.00 & 0.00 & $-\operatorname{Inf}$ & Inf & 0.2780 & -55.92 \\
\hline 3 RIC 108 & & BUS_11 & & & 0.00 & 0.00 & 0.00 & & tilt & & 81.64 \\
\hline 4 RiC 108 & & BUS_12 & 0.00 & & 0.00 & 0.00 & 0.00 & $-\operatorname{Inf}$ & Inf & 1.861 & 65.78 \\
\hline 5 RiC 108 & & BUS 13 & 0.00 & & 0.00 & 0.00 & 0.00 & $-\operatorname{Inf}$ & Inf & 1.7788 & 67.9 \\
\hline 6 RIC 108 & & BUS 14 & 0.00 & & 0.00 & 0.00 & 0.00 & $-\operatorname{Inf}$ & Inf & 1.1533 & 82.8 \\
\hline 7 RIC 108 & & $\mathrm{BOS}_{3} 3$ & & & 0.00 & 0.00 & 0.00 & $-\operatorname{Inf}$ & Inf & & -93.22 \\
\hline 8 RiC 10a & & BOS 4 & 0.00 & & 0.00 & 0.00 & -0.00 & $-\operatorname{In}$ & $\operatorname{Inf}$ & 0.0636 & 102.6 \\
\hline 9 RiC los & & BOS 5 & 0.00 & & 0.00 & 0.00 & 0.00 & $-\operatorname{In}$ & Inf & 0.100 & 109.6 \\
\hline 10 RiC 108 & & BOS 6 & 0.00 & & 0.00 & 0.00 & 0.00 & $-\operatorname{Inf}$ & Inf & 1.7732 & 74.1 \\
\hline 11 Bus & - & BOS ? & 0.00 & & 0.00 & 0.00 & 0.00 & 0.00 & 0.00 & 0.4104 & 102.6 \\
\hline 12 Bus & - & BUS 8 & 0.00 & & 0.00 & 0.00 & 0.00 & & 0.00 & & 0.0 \\
\hline 13 RIC 108 & & BOS 9 & 0. & & 0.00 & 0.00 & 0.00 & & Inf & & 74.4 \\
\hline 14 RIC 108 & & BOS 10 & 0.00 & & 0.00 & 0.00 & 0.00 & $-\operatorname{Inf}$ & $\operatorname{Inf}$ & 0.9668 & 77.4 \\
\hline 15 Varc & $\mathrm{pN}$ & $1 *$ & 0.00 & & 0.00 & 0.00 & 23.40 & 0.00 & 0.00 & 0.7415 & -124.6 \\
\hline 16 Vare & swing & $t^{*}$ & 0.00 & & 0.00 & 0.00 & -0.00 & 0.00 & 0.00 & 1 & 0.0 \\
\hline 17 Vysc & $\mathbb{P N}$ & ${ }^{* 3 *}$ & 0.0 & & 0.00 & 0.00 & 0.00 & -0.00 & 0.00 & 0 & 0.0 \\
\hline 18 Varc & $\mathrm{PV}$ & $44^{*}$ & & & 0.00 & 0.00 & 0.00 & & .00 & 0.7958 & -77.2 \\
\hline 19 Vsrc & $\mathrm{PV}$ & $5^{*}$ & 0.00 & & 0.00 & 0.00 & 23.40 & -0.00 & 0.00 & 0.4374 & 41.9 \\
\hline
\end{tabular}

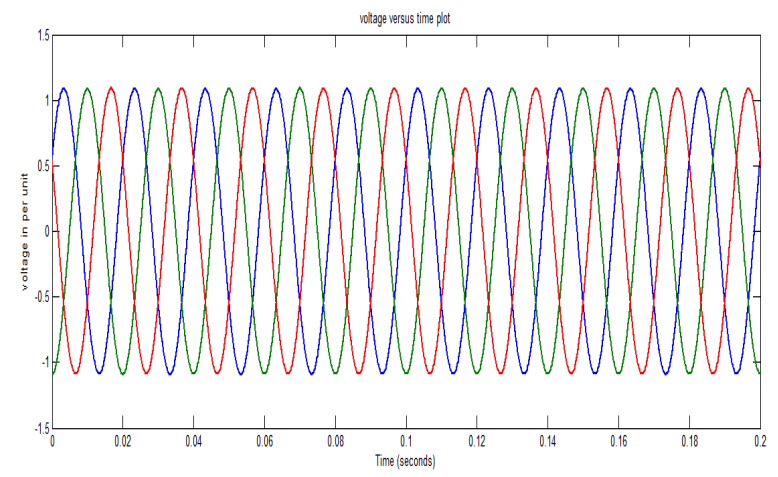

Figure 12: Voltage at bus 8 after connecting DVR

\section{CONCLUSION}

By observing the above results, after connecting the dynamic voltage restorer in series with the affected bus that is bus number 7 , the voltage profile has been improved very well and smooth wave of all the three phases has been obtained as shown in the figure 12 . Hence by this paper we can conclude that a dynamic voltage restorer is very efficient device in improving the voltage profile of the system unlike STATCOM.

\section{REFERENCES}

1. Study of transient voltage stability with transient stability probing method in hunan power grid by jian zuo in 2017 4th international conference on systems and informatics (icsai).

2. Study of the application of active power adjustment and control technology based on modem energy storage into power system stability control and voltage adjustment by Xiaohui Qin in 2014 International Conference on Power System Technology.

3. Dynamic grid support in low voltage grids - fault ride-through and reactive power/voltage support during grid disturbances by Gustav Lammert in 2014 Power Systems Computation Conference.

4. The impact of distributed wind power generation on voltage stability in distribution systems by Jingxu Yang 2013 IEEE PES Asia-Pacific Power and Energy Engineering Conference (APPEEC)

5. Dynamic Voltage Stability Improvement using coordinated control of dynamic VAR-sources by Ghadir Radman in 2007 iREP Symposium - Bulk Power System Dynamics and Control - VII. Revitalizing Operational Reliability

6. Mechanism Research of Short-Term Large-Disturbance Voltage Stability by Tang Yong in 2006 International Conference on Power System Technology

7. Transient Stability using Energy Function Method in Power Systems Close to Voltage Collapse by Manfred F. Bedrinana in 2007 Large Engineering Systems Conference on Power Engineering.

8. Power Transmission Path Analysis of Voltage Stability in Shandong Power System by Liang Wang in 2006 International Conference on Power System Technology.

9. Automatic street light control system with and without internet of things by polamreddy girija, Palvoi kishore baby, gudumcherla girija, B venkateshnaik in inthernational journal of emerging trends in engineering research(IJETER). 10. Calculation or reinforced concrete beams by smirnova zanna,V. vaganova O.I, Cherny O.T, kutupova L I in inthernational journal of emerging trends in engineering research(IJETER). 